\title{
Anthropic land use causes summer cooling in Central Europe
}

\author{
M. Zampieri ${ }^{1}$, P. Lionello ${ }^{2,3, *}$ \\ ${ }^{1}$ ISAC-CNR, Via per Arnesano km 1.2, 73100 Lecce, Italy \\ ${ }^{2}$ Dept. of Material Sciences, University of Salento, Via per Arnesano km 1.2, 73100 Lecce, Italy \\ ${ }^{3}$ CMCC, Via Augusto Imperatore 16, 73100 Lecce, Italy
}

\begin{abstract}
The diagnostic potential natural vegetation (PNV) model, VERDE (Vegetation Reconstruction by Diagnostic Equilibrium), recently developed by the authors, is coupled to the Italian regional climate model (RegCM) ICTP, and is implemented in the European and Mediterranean regions. This study assesses the effect of anthropic land use on the present-day climate in these regions, and computes the climate associated with the PNV through iteration of a 2-step procedure, composed of a multi-annual model simulation and subsequent computation by VERDE of the PNV corresponding to the simulated climate. In the first iteration, RegCM adopts the present land use (which over Europe is dominated by crops and farming, with very little natural vegetation). The procedure is iterated until there is no appreciable difference between the PNV used by RegCM, and that associated with the climate that it produces, so that the PNV and model climate are consistent. The equilibrium PNV consists mainly of shrubs in the Mediterranean and deciduous broadleaf forest in central Europe. The effect of anthropic land use on climate is assessed by analyzing the difference between the simulated present-day anthropic land use and PNV climates, which is given by the difference between the first and the last iterations of the procedure. We found that anthropic land use produces cooler summers, and identified 2 different mechanisms: (1) over the Balkan Peninsula, anthropic land use modifies the surface energy balance by increasing evapotranspiration; (2) over central-western Europe, cooling is mostly due to cloudier sky conditions. These results show: (1) that reforestation may not be appropriate as a tool for climate change mitigation at the regional scale, and (2) expansion of agricultural land use may have reduced past warming signals at the regional scale, though historical records of land-use evolution suggest that this effect is probably small for Europe during the 20th century.
\end{abstract}

KEY WORDS: Land cover $\cdot$ Potential vegetation $\cdot$ Anthropic land use $\cdot$ Regional climate

\section{INTRODUCTION}

The purpose of this study is to analyze the effect of the anthropic land use on the European climate. Since a large fraction of European land is used for crops and farming (which occupy $26.7 \%$ of grid points; see Fig. 1a), the present-day land cover is very different from that associated with potential natural vegetation (PNV), which is the vegetation that would exist as a result of climatic factors, in absence of a direct anthropic action. The analysis is based on model simulations carried out coupling RegCM (Giorgi et al. 1993a,b, Pal et al. 2000) - a regional climate model
(RCM) - to VERDE (Vegetation Reconstruction by Diagnostic Equilibrium, a statistical model for the computation of land cover types, LCT; Zampieri \& Lionello 2010) and to PNV. Both models are briefly described in section 2 . The inclusion of vegetation dynamics and feedbacks in climate models is established as important for the accurate simulation of the climate system (e.g. Claussen 1998, Foley et al. 1998), and is needed for the description of the Earth's surface properties (e.g. Sellers et al. 1997). Since changes in vegetation produce changes in albedo (Charney et al. 1977), evapotranspiration rate, and surface roughness (e.g. Sellers 1992, Henderson-Sellers et al. 1995), it is worth 
exploring their effects on the regional European climate. The results of this study could be relevant for the interpretation of past climate records, and to evaluate the effects of reforestation and natural vegetation regrowth on climate change over Europe (see Bonan 2008 for a general discussion on these topics).

Characteristics of plants have effects on the properties of the Earth surface that are represented in climate models, affecting many processes, particularly, evapotranspiration. An important property of plants is their stomatal resistance. Among the plant types describing the surface properties in RegCM (see Table 1 and Dickinson et al. 1993), 'crops and farms' have the lowest minimum stomatal resistance $\left(45 \mathrm{~s} \mathrm{~m}^{-1}\right.$, which is the same as 'irrigated crops' and 'bogs-marshes') followed by 'grass' and 'tropical vegetation' $\left(60 \mathrm{~s} \mathrm{~m}^{-1}\right)$, 'needle leaf trees', 'tundra' and 'evergreen shrubs' $\left(80 \mathrm{~s} \mathrm{~m}^{-1}\right)$, 'broadleaf deciduous tree' and other vegetated land use $\left(120 \mathrm{~s} \mathrm{~m}^{-1}\right)$. Actual stomatal resistance is computed by multiplying the minimum stomatal resistance by non-linear factors (Dickinson et al. 1993), which take into account the influence of solar radiation, temperature and water vapour deficit on the leaf biochemistry, and is limited to a maximum value of $20000 \mathrm{~s} \mathrm{~m}^{-1}$, which in our simulations is reached only in winter in north-eastern Europe. Decreasing stomatal resistance (i.e. increasing conductance) increases evapotranspiration (Henderson-Sellers et al. 1995). Foliage characteristics, such as leaf area index (LAI), are also important for the amount of leaf surface that can transpirate (Dickinson et al. 1993) so that evapotranspiration in- creases with LAI. In this respect, the replacement in summer of grass (which in RegCM simulations has a maximum LAI of 2) with other plant functional types (most of which - e.g. crops - have a maximum LAI of 6) has important effects on evapotranspiration. Therefore, the replacement of PNV with crops in general reduces stomatal resistance and increases LAI, and both effects, if water is available in the soil, increase evapotranspiration. Furthermore, when crops replace broadleaf trees or grass, they increase surface albedo (because of changes in LAI, leaf orientation, leaf and stem reflectance). Finally, replacement of forests with crops implies reduction of surface roughness, which may trigger systematic effects on atmospheric circulation (Pitman et al. 2004).

Some previous studies have analyzed the effect of reforestation and disproved its alleged role as a potential tool for mitigating climate change at global scale, mostly because it would reduce albedo at temperate and high latitudes (e.g. Bonan et al. 1995). However, in the tropics, where the snow-masking effect of forests is absent, reforestation might reduce temperatures up to $2^{\circ} \mathrm{C}$ (Feddema et al. 2005, Sitch et al. 2005), because of an increased evapotranspiration rate of highly productive forests compared to agricultural lands, and a decreased flux of sensible heat (e.g. Betts 2000, Feddema et al. 2005, Gibbard et al. 2005, Sitch et al. 2005, Bala et al. 2007, Betts et al. 2007; for a short synthesis, see Christensen et al. 2007).

Model simulations show that modern (anthropic) land use changes have reduced surface roughness, reduced

Table 1. Maximum fractional vegetation cover (FVC), difference between max fractional vegetation cover and cover at $269 \mathrm{~K}$, roughness length, minimum stomatal resistence, maximum and minimum leaf area index, and vegetation albedo (at different wave lengths), for the main land cover types used by BATS (Biosphere-Atmosphere Transfer scheme), in the European and Mediterranean regions

\begin{tabular}{|c|c|c|c|c|c|c|c|c|}
\hline & \multirow{2}{*}{$\begin{array}{l}\text { Max. } \\
\text { FVC }\end{array}$} & \multirow[t]{2}{*}{$\Delta \mathrm{FVC}$} & \multirow{2}{*}{$\begin{array}{l}\text { Roughness } \\
\text { length (m) }\end{array}$} & \multirow{2}{*}{$\begin{array}{l}\text { Min. stomatal } \\
\text { resistance } \\
\left(\mathrm{s} \mathrm{m}^{-1}\right)\end{array}$} & \multicolumn{2}{|c|}{ Leaf area index } & \multicolumn{2}{|c|}{${ }_{-}$Albedo- } \\
\hline & & & & & Max. & Min. & $(<0.7 \mu \mathrm{m})$ & $(>0.7 \mu \mathrm{m})$ \\
\hline Crops / mixed farming & 0.85 & 0.6 & 0.08 & 45 & 6 & 0.5 & 0.1 & 0.3 \\
\hline Short Grass & 0.8 & 0.1 & 0.05 & 60 & 2 & 0.5 & 0.1 & 0.3 \\
\hline Evergreen needle leaf trees & 0.8 & 0.1 & 1.00 & 80 & 6 & 5 & 0.05 & 0.23 \\
\hline Deciduous needle leaf trees & 0.8 & 0.3 & 1.00 & 80 & 6 & 1 & 0.05 & 0.23 \\
\hline Deciduous broad leaf trees & 0.8 & 0.3 & 0.80 & 120 & 6 & 1 & 0.08 & 0.28 \\
\hline Evergreen broad leaf trees & 0.9 & 0.5 & 2.00 & 60 & 6 & 5 & 0.04 & 0.2 \\
\hline Tall grass & 0.8 & 0.3 & 0.10 & 60 & 6 & 0.5 & 0.08 & 0.3 \\
\hline Desert & 0 & 0 & 0.05 & 200 & 0 & 0 & 0.2 & 0.4 \\
\hline Tundra & 0.6 & 0.2 & 0.04 & 80 & 6 & 0.5 & 0.1 & 0.3 \\
\hline Irrigated crop & 0.8 & 0.6 & 0.06 & 45 & 6 & 0.5 & 0.08 & 0.28 \\
\hline Semi-desert & 0.35 & 0.1 & 0.1 & 150 & 6 & 0.5 & 0.17 & 0.34 \\
\hline Ice cap and glaciers & 0 & 0.0 & 0.01 & 200 & 0 & 0 & 0.8 & 0.6 \\
\hline Bogs and marches & 0.8 & 0.4 & 0.03 & 45 & 6 & 0.5 & 0.06 & 0.18 \\
\hline Evergreen shrubs & 0.8 & 0.2 & 0.1 & 80 & 6 & 5 & 0.05 & 0.23 \\
\hline Deciduous shrubs & 0.8 & 0.3 & 0.1 & 120 & 6 & 1 & 0.08 & 0.28 \\
\hline Mixed woodland & 0.8 & 0.2 & 0.8 & 100 & 6 & 3 & 0.06 & 0.24 \\
\hline Forest-field mosaic & 0.8 & 0.4 & 0.3 & 120 & 6 & 0.5 & 0.06 & 0.18 \\
\hline
\end{tabular}


leaf and stem area index, reduced stomatal resistance, and increased surface albedo producing a large summer cooling ( 1 to $2 \mathrm{~K}$ ) in the eastern and central USA (Bonan 1997). At a global scale, higher albedo associated with crops has been found to be responsible for a $0.25 \mathrm{~K}$ global ( $0.37 \mathrm{~K}$ for the northern hemisphere) cooling (Govindasamy et al. 2001). Other effects may be at play. The effect of land cover changes on the climate of southwest Australia (decrease in precipitation) has been associated with large-scale changes of atmospheric flux convergence/divergence (Pitman et al. 2004) due to the change in surface roughness. Extrapolation of a sparse set of observations restricted to the United States revealed a $0.27 \mathrm{~K}$ warming per century due to urban and other land-use changes (Kalnay \& Cai 2003). However, few studies (Heck et al. 2001) have addressed Europe, which is, perhaps, the region of the world with the most intense anthropic land use.

The aim of this study is to analyze the importance of LCTs in Europe at the regional scale, and their effects on regional dynamics, assessing their importance across Europe and the dependence of these effects on season. Effects on albedo, evapotranspiration, and surface drag overlap in an a priori non-obvious way, so that a realistic model is needed to identify the dominant mechanism and its quantitative relevance. This analysis is based on regional climate simulations, and compares the present-day anthropic climate (computed adopting the present land use), to the climate calculated from the PNV conditions.

\section{METHODS AND MODEL VALIDATION}

The climate simulations are carried out with RegCM (Giorgi et al. 1993a,b, Pal et al. 2000) driven at the boundaries by fields from the ERA-40 reanalysis (Simmons \& Gibson 2000). The RegCM model grid spacing is approximately $55.5 \mathrm{~km}$, and the model domain covers the European region and adjacent oceans. The analysis is mainly focused on the $10 \mathrm{yr}$ period, 1 Jan 1992 to 31 Dec 2001, but also results from another 10 yr period, 1 Jan 1982 to 31 Dec 1991, and is discussed in Section 4, where the analysis is integrated with short simulations for the period from 1 Jan 1993 to 31 Dec 1995.

The description of the LCT in the RegCM is based on the BATS (Biosphere-Atmosphere Transfer Scheme, Dickinson et al. 1993, Yang \& Dickinson 1996) version $1 \mathrm{e}$, which describes the role of vegetation and interactive soil moisture in modifying the surface-atmosphere exchanges of momentum, energy, and water vapour. The model has 5 layers: a vegetation layer, a snow layer, a surface soil layer (10 cm thick), a root zone layer (1 to $2 \mathrm{~m}$ thick) and a deep soil layer ( $3 \mathrm{~m}$ thick). BATS accounts for precipitation, snowmelt, canopy foliage drip, evapotranspiration, surface runoff, infiltration below the root zone, and diffusive exchange of water between soil layers. BATS has 20 vegetation types with soil textures ranging from coarse (sand), to intermediate (loam), to fine (clay), and different soil colours (light to dark) for the soil albedo calculations. A percent of land coverage is attributed for every grid point to each LCT. In the adopted version of the model, the surface characteristics of each grid point are determined by the LCT to which the largest percentage is attributed. This simplification might imply an overestimation of the effect of anthropic LCT on present climate. The characteristics of the main cover types describing the land surface in the European and Mediterranean regions, already discussed in the introduction, are shown in Table 1.

Present-day LCTs used by RegCM are derived from the Global Land Cover Characterization (GLCC) datasets for the vegetation/landuse data, which, in turn, are derived from $1 \mathrm{~km}$ advanced very high resolution radiometer (AVHRR) data spanning April 1992 through March 1993 (Eidenshink \& Faundeen 1994).

The PNV computation is based on the VERDE model (Zampieri \& Lionello 2010). VERDE is a purely statistical and diagnostic model, which uses the observed links between vegetation types and climate for computing the spatial distribution of vegetation from the average annual cycle of monthly precipitation and mean temperature. It aims at describing only the equilibrium condition of vegetation, without any attempt to describe its time evolution. Moreover, VERDE is targeted at the representation of vegetation in climate models for the purpose of describing surface properties that are important for computing fluxes and atmospheric circulation. VERDE is an application of cluster analysis, where climate conditions and land cover types are grouped by an automatic and objective procedure. The idea is to identify - within the distribution of climates and vegetation-similar conditions that can be represented by a centroid associated with each cluster, according to the metrics that we defined in Appendix A of Zampieri \& Lionello (2010). In this study, VERDE adopts the BATS classification of LCTs to compute the PNV. This implies that the PNV will only be represented by the natural (non-anthropic) surface types that are shown in Table 1. Details of VERDE and its validation at the global scale can be found in Zampieri \& Lionello (2010). Its comparison with the PNV produced by Ramankutty \& Foley (1999) shows that the 2 reconstructions match reasonably well, except for (1) a much larger extension of wood-savanna, which VERDE predicts over central France and around the southern coast of the Baltic Sea, and (2) large areas of savanna instead of deciduous forest over India. 

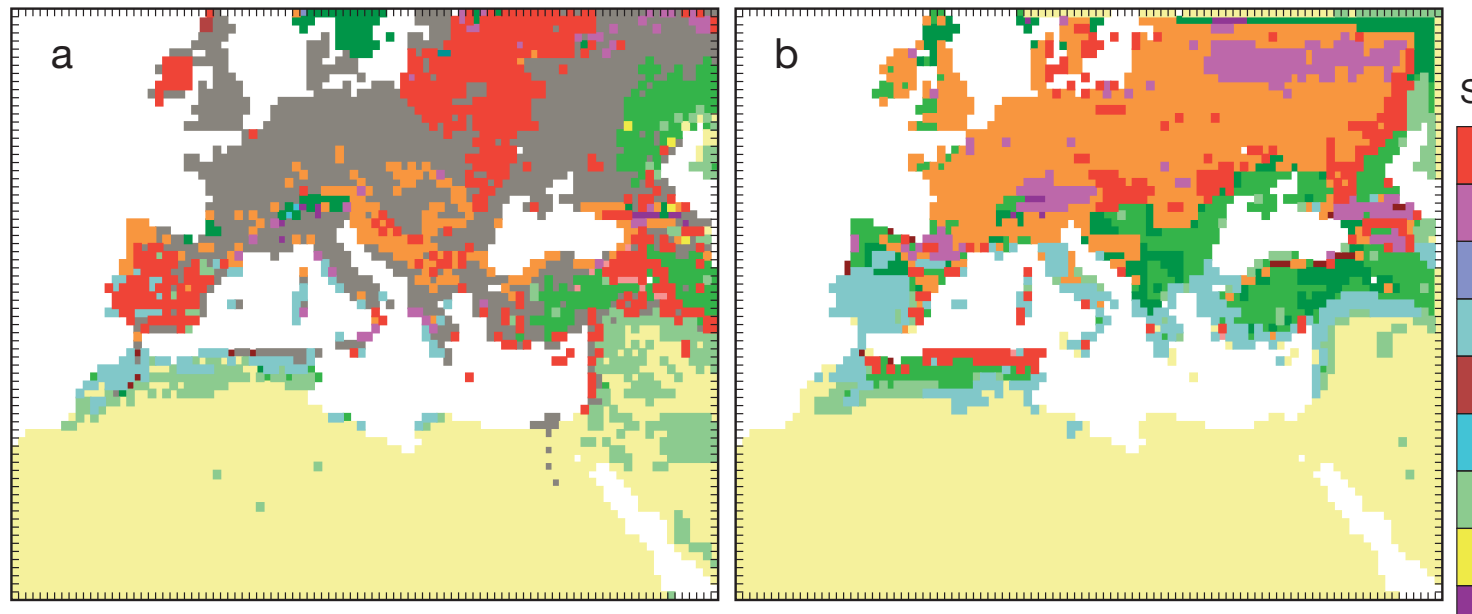

Soil cover type
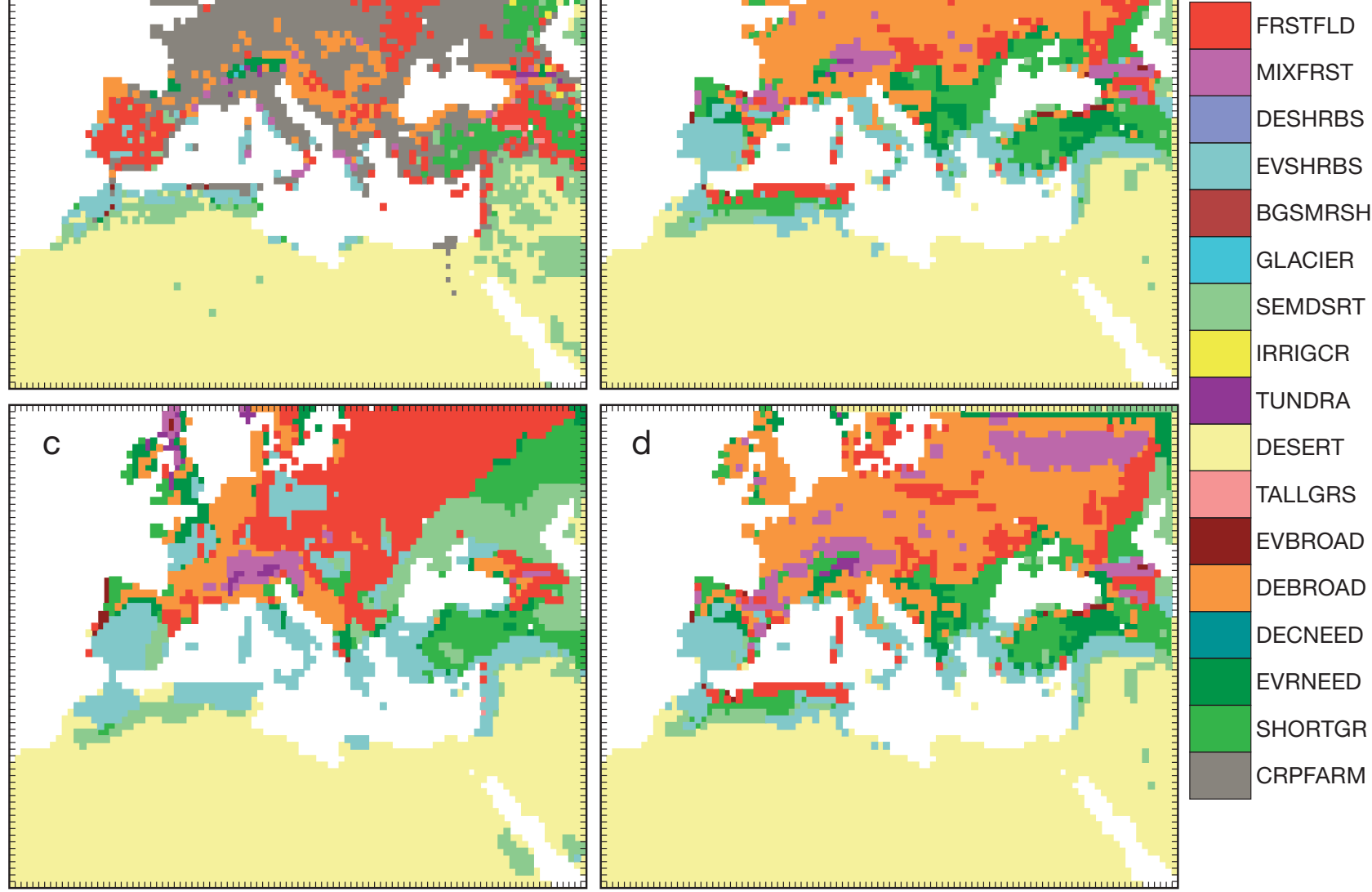

Fig. 1. (a) Present-day anthropic vegetation and land use, (b) PNV (potential natural vegetation) in equilibrium with the regional climate, (c) PNV associated with the CRU (Climate Research Unit observational data of the University of East Anglia, Norwich, UK) climatology, and (d) PNV associated with the present-day RegCM (regional climate model developed by ICTP, Italy) climate (but not in equilibrium with it). Soil cover types in colour bar are, from top to bottom: forest field (forest-field mosaic), mixed forest, deciduous shrubs, evergreen shrubs, bogs and marshes, ice caps and glaciers, semi-desert, irrigated crops, tundra, desert, tall grass, evergreen broadleaf trees, deciduous broadleaf trees, deciduous needle-leaf trees, evergreen needle-leaf tree, short grass, crops and farms

The method for computing the climate associated with the PNV is based on the iteration of a procedure consisting of 2 steps: a $10 \mathrm{yr}$ simulation with RegCM, and of the subsequent computation by VERDE of the PNV corresponding to the simulated annual cycles of temperature and precipitation. These 2 steps are iterated until there is no appreciable difference between the PNV used by RegCM and that associated with the climate it produces. In the first iteration RegCM adopts the present land use (which over Europe is dominated by crops and farms, with very little natural vegetation), and computes the anthropic climate. The comparison between the climate of the first iteration (ANTcli) and that of the last one (PNVcli) - simulated present-day anthropic land use climate and PNV climate, respectively - at the end of which the computed PNV is in equilibrium with the regional climate conditions, gives the effect of the anthropic land use on the regional cli- mate. This approach produces consistent vegetation (land cover) and climate, and in this respect it is different from studies where land cover is imposed (Kueppers et al. 2007).

The validation of the model ANTcli is based on the comparison against the CRU (Climate Research Unit) observational data of the University of East Anglia, Norwich, UK (New et al. 2000). We compare the mean $2 \mathrm{~m}$ temperature and the precipitation fields, respectively (see Figs. $2 \& 3$ ). Over large parts of Europe, the temperature differences are not significant. With respect to CRU, in winter the model is slightly cooler (warmer) over northern Africa (central Europe), suggesting a smaller underestimate of the meridional temperature gradient. In summer, the model is warmer over North Africa, the Middle East and south-eastern Europe, but cooler over western Europe. The RegCM simulation tends to overestimate precipitation, almost 
Temperature $\left({ }^{\circ} \mathrm{C}\right)$
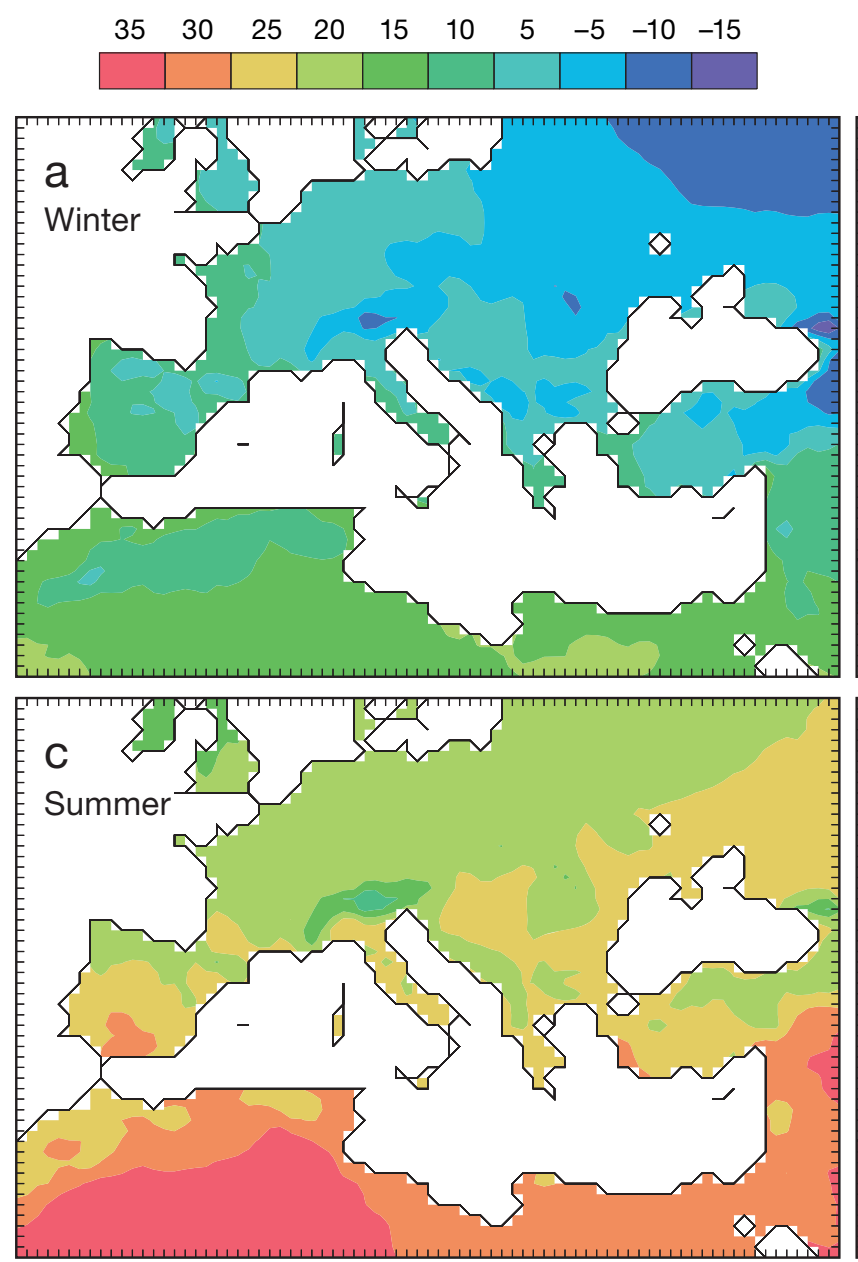

Temperature difference $\left({ }^{\circ} \mathrm{C}\right)$

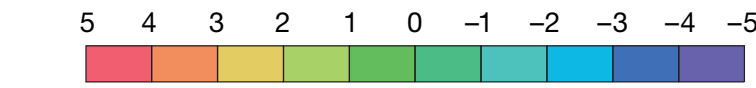

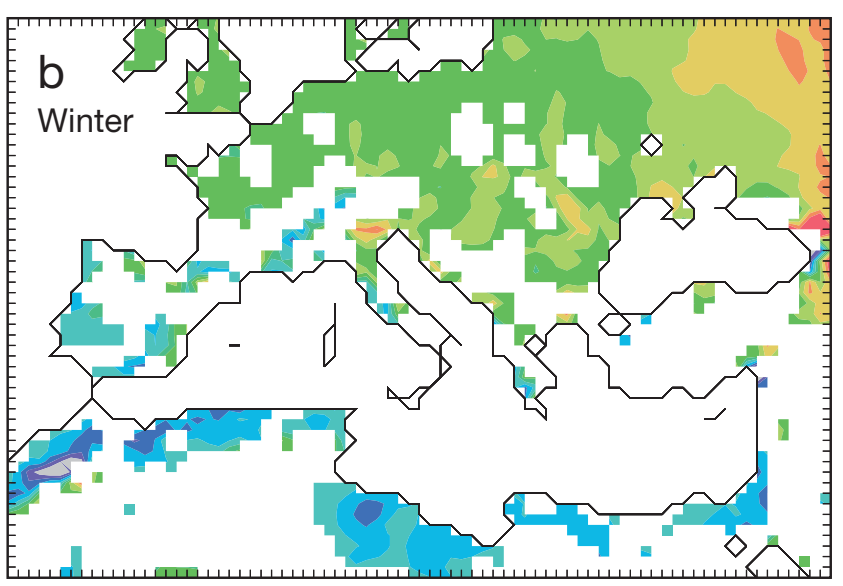

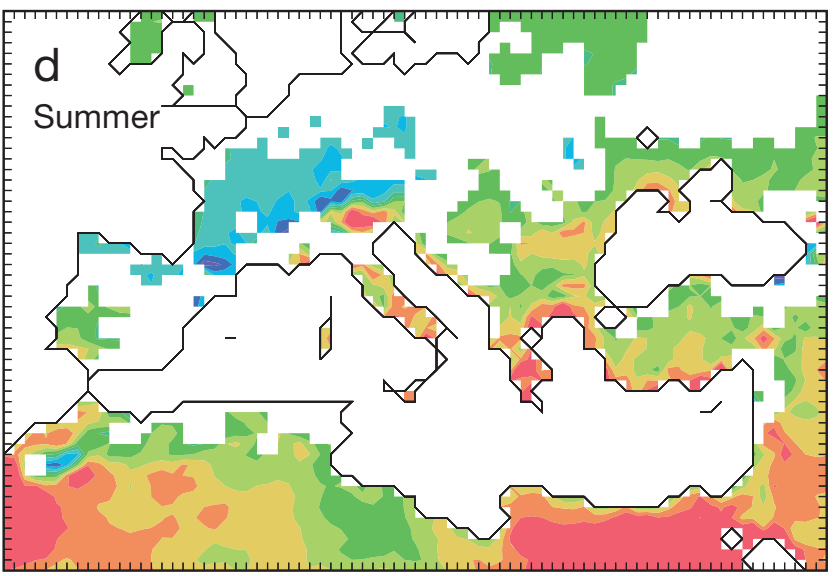

Fig. 2. Comparison between RegCM and the observed climate for the period 1992-2001. (a,c) $2 \mathrm{~m}$ temperature (CRU); (b,d) $2 \mathrm{~m}$ temperature difference (RegCM minus CRU); $(\mathrm{a}, \mathrm{b})$ winter (Dec-Jan-Feb); (c,d) summer (Jun-Jul-Aug). Coloured areas: differences are statistically significant at the $90 \%$ level

everywhere, both in summer and in winter. Differences are important on the northern side of the Alps and inner Anatolia in winter, in the Ebro Valley, the Atlas Mountains region and eastern Europe in summer. These differences have an effect on the reconstructed PNV. Fig. 1 shows the PNV that VERDE computes using the CRU data (Fig. 1c), and the PNV based on the RegCM present climate (Fig. 1d), with anthropogenic effects. Note that, as CRU in the period 1992-2001 accounts for the effect of anthropic LCTs (not in equilibrium with climate), the PNV associated with the CRU climatology should be compared with the PNV after the first iteration, and not with the PNV at the end of the iteration process. However, note that the difference between the first iteration (Fig. 1d) and the PNV in equilibrium with climate (Fig. 1b) is small, showing that the iterative procedure is converging fast. The comparison between the 2 lower panels in Fig. 1 em- phasizes the differences between the RegCM and the CRU climatologies. Differences are larger over northern Europe, while in the Mediterranean there is a substantial agreement. In the RegCM-based LCT, forest field (i.e. field mosaic with forest) replaces deciduous broadleaf tree over Russia, forest field appears at the Mediterranean coast of northwest Africa, and semidesert replaces short grass north of the Black Sea. These changes in land cover are consistent with differences of temperature (Fig. 2) and precipitation (Fig. 3).

\section{RESULTS}

The PNV computed at the end of the iteration procedure is shown in Fig. 1b. Only 3 steps have been necessary for reaching equilibrium. Differences between successive steps have been assessed using the kappa- 

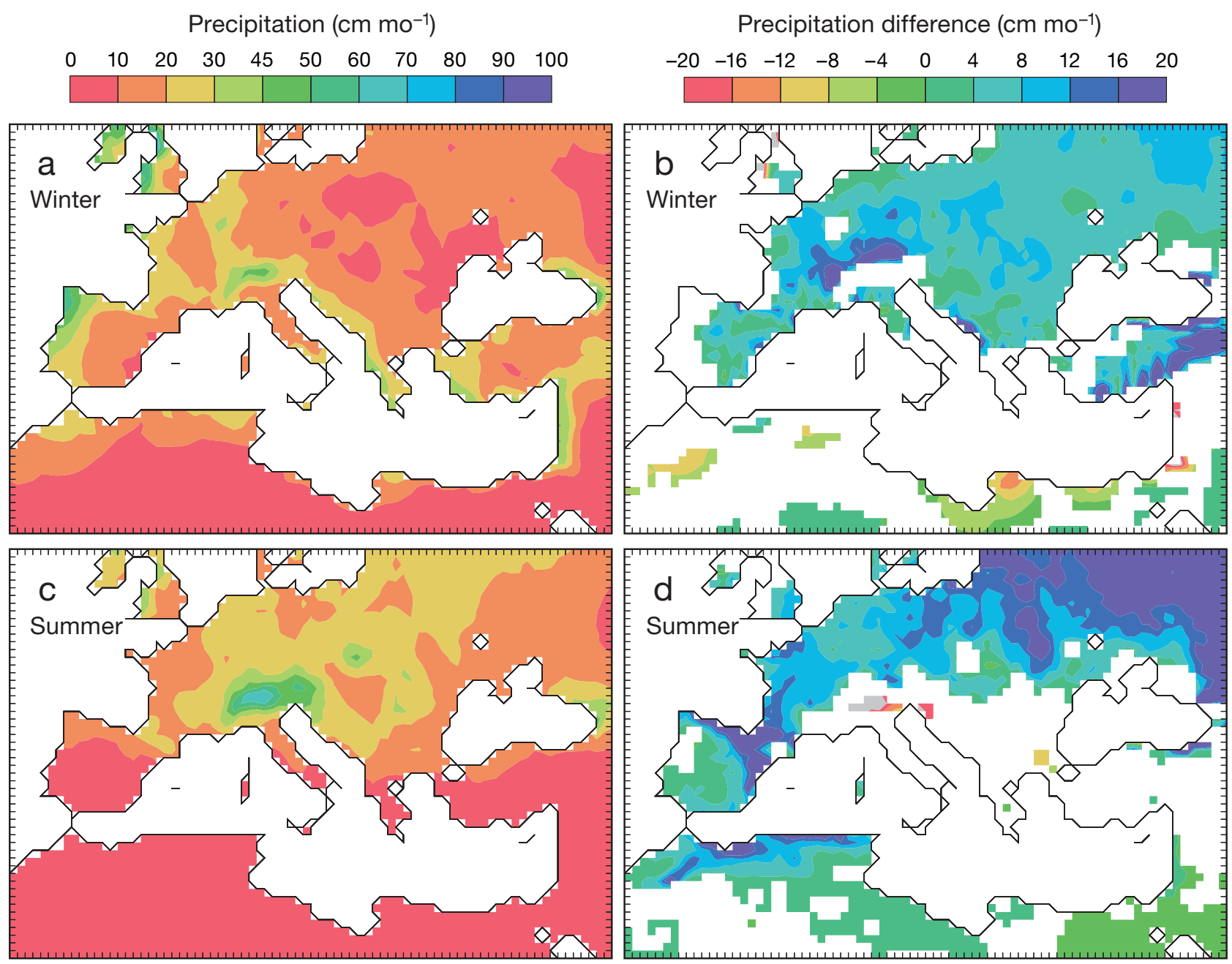

Fig. 3. Comparison between RegCM and the observed climate for the period 1992-2001, for precipitation. Other detail as in Fig. 2

score (Cohen 1960) between successive iterations of the LCT maps, obtaining $0.41,0.90,0.93$, meaning that after the initial big transition from anthropic to natural, LCT changes are small and barely detectable, as can be seen by visual comparison of panels Fig. 1b,d. The equilibrium PNV consists mainly of shrubs in the Mediterranean and of deciduous broadleaf forest in central Europe. The main anthropic features are the replacement-with crops and farming - of a large extension of deciduous broadleaf trees over centralwestern Europe, of short grass over the Balkans and eastern Europe, and of evergreen shrubs over large parts of the Mediterranean region. Sparse areas with mixed forest in central Europe and of evergreen needle leaf trees in eastern Europe have also been replaced with crops and farms. Results for the Balkans are also consistent with observational analysis of pollen data (Willis 1994) that show evidence of anthropic deforestation and import of deciduous broad leaf types of trees in the Greek/Roman times. Because of the low stomatal resistance of crops and farms, these changes increase the evapotranspiration and latent heat loss of the surface. They also increase albedo, and reduce drag over central Europe.

The comparison between ANTcli and PNVcli shows no statistically significant differences for precipitation, while for temperature they are limited to the summer (June-July-August) season. This result is consistent with the paramount forcing exerted by the Atlantic mid latitude storm track on the European climate during the cold season, and the importance of local effects during the warm season. Moreover, vegetation has more of an effect during the growing season, when it strongly influences evapotranspiration and, to a lesser extent, albedo. The intrinsic interannual variability of precipitation limits the potential of soil-cover-related mechanisms to produce a statistically significant effect for the numerically small number of years considered in this study. This reflects the smaller interannual variability and larger sensitivity to climate change of sum- 

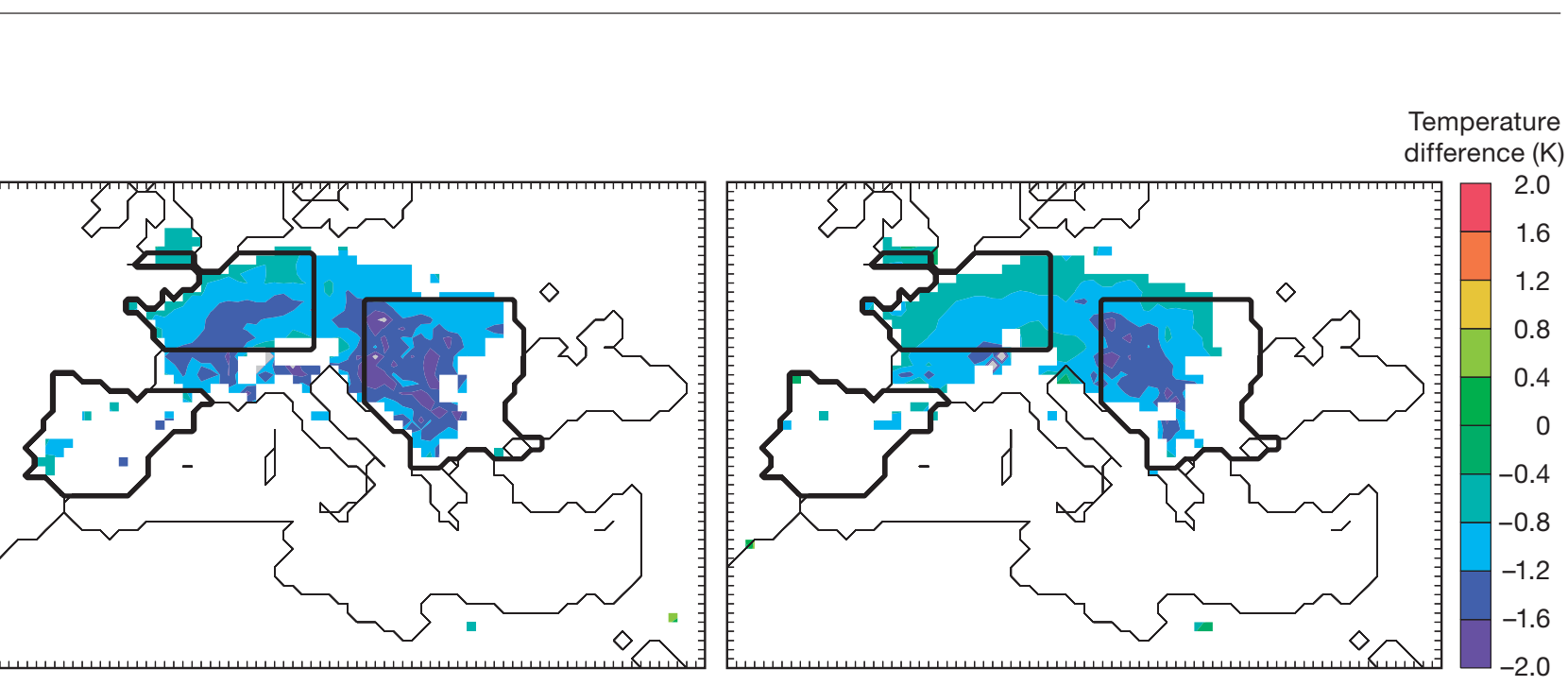

Fig. 4. Jun-Jul-Aug difference between ANTcli and PNVcli (simulated present-day anthropic land use and PNV climates, respectively, for ground and $2 \mathrm{~m}$ temperature (left panel and right panel respectively). Negative values $\left({ }^{\circ} \mathrm{C}\right.$ ) denote areas where the anthropic climate is cooler. Colored areas: differences are statistically significant at the $90 \%$ confidence level. Thick black lines: central-western and southeastern Europe and the Iberian peninsula

mer surface temperature with respect to other variables (Deque et al. 2005).

Fig. 4 shows the difference of $2 \mathrm{~m}$ and ground summer temperature, with a large cooling over central Europe and the Balkan region, and also shows the borders of 3 regions: CWE (central western Europe), SEE (south eastern Europe), Ibe (Iberia). For these regions the mean annual cycles of temperature, radiation, heat fluxes, LAI and stomata resistance during the simulations were computed (Fig. 5). Fig. 5a shows the annual cycle of the $2 \mathrm{~m}$ temperature difference (ANTcli minus PNVcli, with negative values denoting cooling due to anthropic land use), with a trough in June, which reaches about $1.5 \mathrm{~K}$ in the SEE and almost $1 \mathrm{~K}$ in CWE. In Ibe, cooling is weaker, with a trough in July. The signal of temperature (Fig. 5a) is consistent with that of the upwards long-wave flux (Fig. 5d) because of the Stefan-Boltzmann law which states that thermal emission of a body is proportional to the fourth power of its temperature. The temperature signal over SEE and over Ibe is also consistent with that of evapotranspiration in Fig. 5b. Over SSE and Ibe, increased evapotranspiration of crops modifies the energy budget of the surface (though sensible heat changes (Fig. 5c) partially compensate the larger latent heat release) and the surface temperature adjusts to a lower value, so that a lower upward thermal radiation flux (Fig. 5d) is needed to close its overall energy balance. The size and timing of the evapotranspiration change are quite different over SEE and Ibe. In the first case crops replace large areas of grass, in the second case a mixture of forest and fields replaces evergreen shrubs. These differences cause different changes LAI that is much larger over SEE than over Ibe (Fig. 5g). Further, over Ibe, anthropic land use increases stomatal resis- tance (Fig. 5h) in summer, partially compensating the increase of LAI on evapotranspiration. As a consequence, the change in evapotranspiration over Ibe is smaller, and peaks one month later than that over SSE.

The different characteristics of the LCT change are summarized in Table 2, which shows average values for the 3 regions during the entire growing season (from March to August). The different changes of evapotranspiration are related to the different changes of stomatal resistance and LAI. Stomatal resistance decreases in CWE and SEE, and shows a smaller increase over Ibe. LAI increases in all regions, especially in SEE. The effect of the LAI anomaly on evapotranspiration is more important than that of the stomatal resistance, and explains why evapotraspiration also increases in Ibe. Table 2 also shows an increase of albedo over CWE and SEE, a substantial reduction of drag over CWE and of solar radiation (meaning increased cloudiness) over all 3 regions. The reduction of solar radiation is especially large over CWE compared to the other regions.

The highest degree of cooling (i.e. the lowest amount of warming) during the growing season is found in CWE. The mean temperature difference is largest over SEE and smallest over Ibe. This is explained by the energy budget analysis shown in Table 2. Latent-heatinduced cooling is the main factor for SSE, and produces the largest ground-and $2 \mathrm{~m}$ (not shown)temperature anomaly among the 3 regions. Decreased incoming solar radiation is the main factor for CWE, where the largest anomaly of the temperature variation between March and August is observed. In CWE cooling is comparable with that over SEE, in spite of a low evaporanspiration signal. The large reduction (about $20 \mathrm{~W} \mathrm{~m}^{-2}$; Fig. 6) of incoming solar radiation is partially attenuated by a corresponding increase (about 

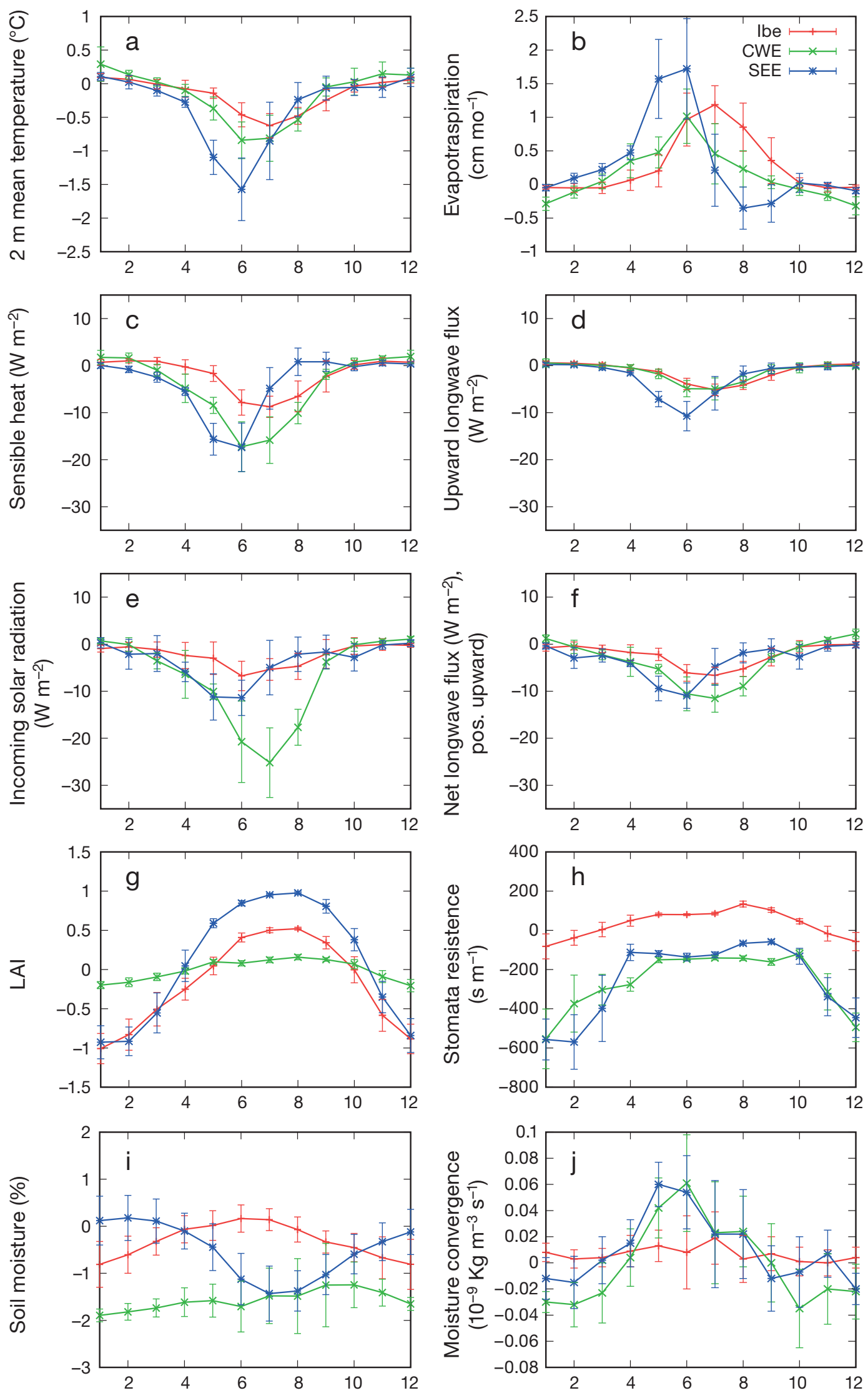

Fig. 5. Annual cycle difference between ANTcli and PNVcli for CWE (central-western Europe), SEE (southeastern Europe), Ibe (Iberia). (a) $2 \mathrm{~m}$ temperature, (b) evapotranspiration, (c) sensible heat, (d) long wave upward radiation flux, (e) incoming solar radiation, (f) net long wave radiation flux, (g) Leaf area index (LAI), (h) stomatal resistance, (i) volumetric soil moisture (\%), (j) moisture transport convergence at $950 \mathrm{hPa}$. Bars denote the interannual standard deviation of the differences 


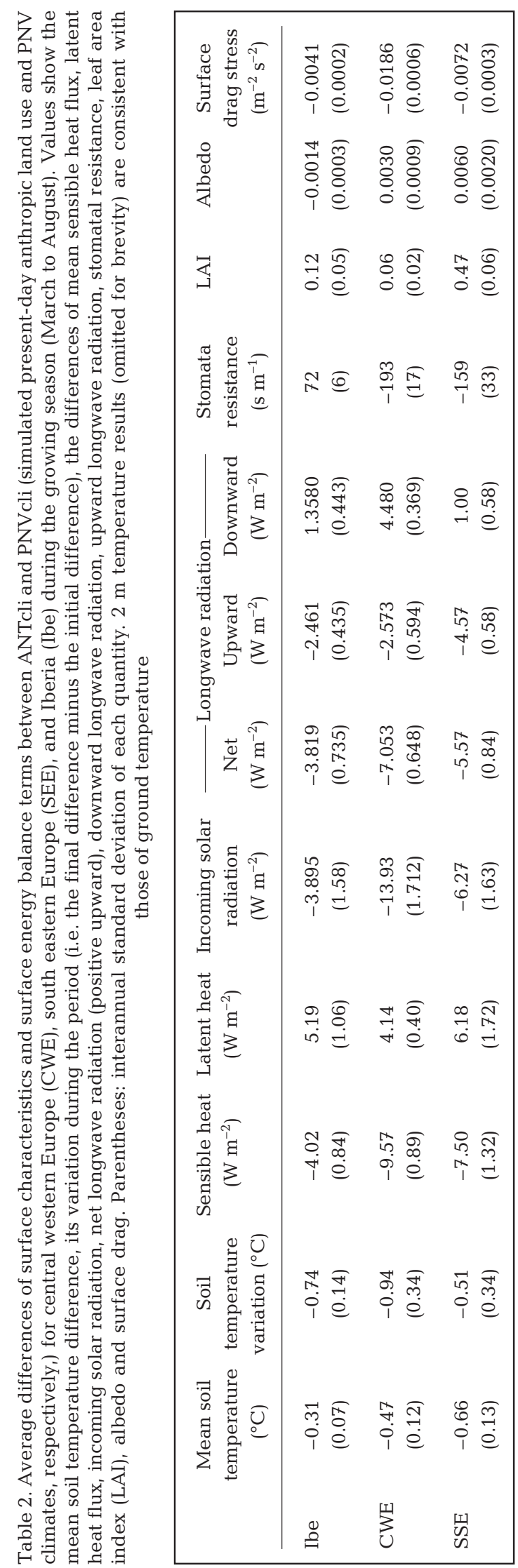

$10 \mathrm{~W} \mathrm{~m}^{-2}$ ) of net longwave radiation, determining the cooling over CWE. In other words, evapotranspiration directly cools SEE from May to June, while increased cloudiness cools CWE from June to August. The different forcing exerted by evapotraspiration is also evident from the volumetric soil moisture annual cycles for the 3 regions, shown in Fig. 5i. The intense anomaly that is produced for CWE is almost constant along the annual cycle, meaning that a different equilibrium exists in the ANTcli and PNVcli simulations, while the soil moisture anomalies in Ibe and SEE show a large annual cycle whose amplitude is larger in SEE, where soil moisture reaches its minimum value in July and August. In this period soil moisture is acting as a limiting factor for evapotranspiration in SEE, explaining the reversing of the evapotranspiration anomaly sign at the end of the growing season, and the reduction in cooling.

\section{DISCUSSION}

The results of this study show substantial differences among the 3 considered regions (Ibe, CWE, SEE) with only 2 of them showing a major and robust cooling effect. For SEE, the cooling effect is explained by a local process: increased evapotranspiration. For CWE this effect is not sufficient, and increased cloudiness is a key factor explaining the cooling. Note that evapotranspiration and cloudiness increase in all 3 regions, but not at the same level, with the increase of evapotranspiration and cloudiness being particularly large over SEE and CWE, respectively (Table 2).

One mechanism explaining increased cloudiness could be the decrease in the lifting condensation level (LCL), which is the altitude at which condensation occurs and cloud formation is initiated, and coincides with the cloud base height. Pinto et al. (2009) have shown that decreased air temperature and increased atmospheric moisture content result in a lowering of LCL, which could make cloud formation more efficient in ANTcli than in PNVcli. This process is likely more effective over France than over the Balkans because of higher moisture arriving from the Atlantic, with respect to dry inland conditions over the Balkans in summer. Alternatively, increased cloudiness could be linked to a feedback involving circulation, and is probably produced by either or both of the following 2 factors: (1) reduced drag, which favours penetration of air from the Atlantic into central Europe, and (2) increased pressure, which partially blocks the flow further downstream. Fig. 7 shows the presence of a significant high pressure associated with cooling over central Europe. This is a thermal feature, localized in the lower troposphere, which is not present at higher levels (e.g. in the $850 \mathrm{hPa}$ or higher geopotential fields) and has the likely 


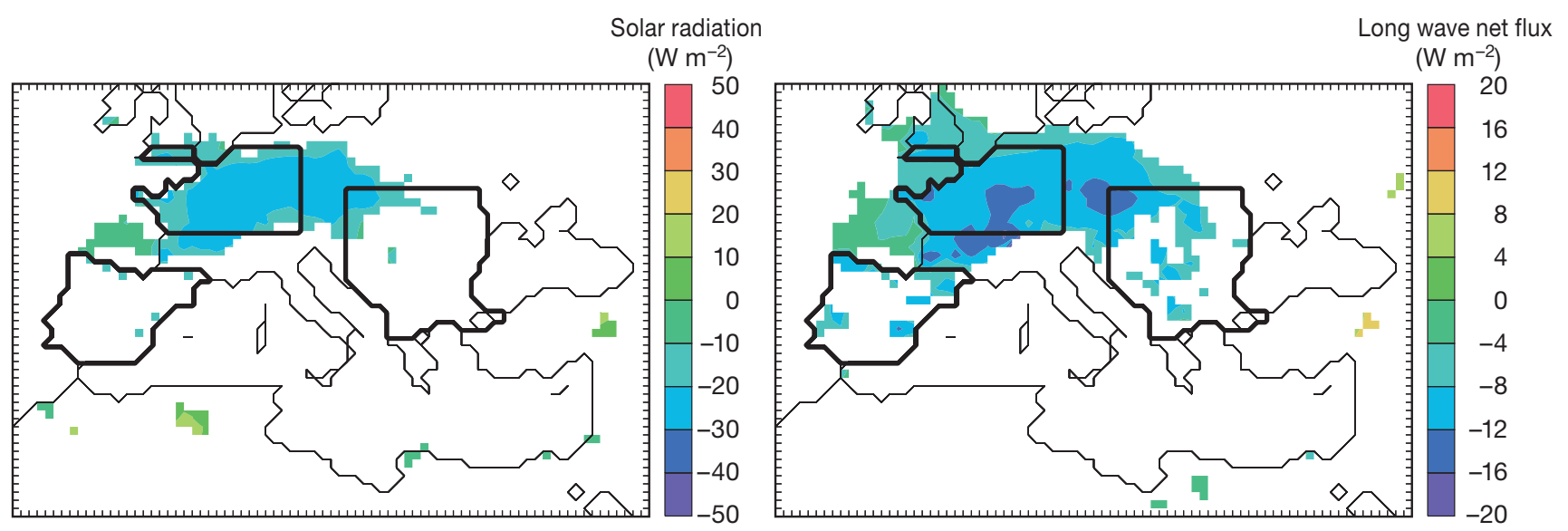

Fig. 6. Jun-Jul-Aug difference between ANTcli and PNVcli for incoming solar radiation and long wave net flux (left and right panels, respectively). Negative values: areas where the anthropic climate is cloudier (left panel) and where green house effects are stronger (right panel). Coloured areas: differences are statistically significant at $90 \%$

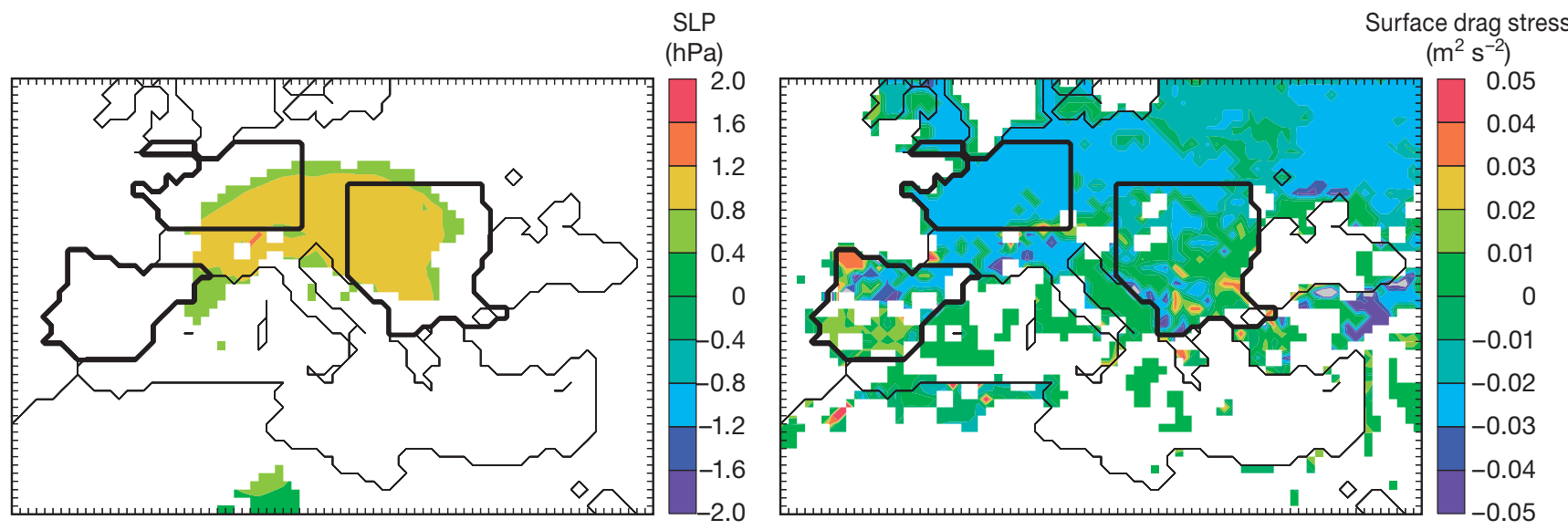

Fig. 7. Jun-Jul-Aug difference between ANTcli and PNVcli mean sea-level pressure (SLP) (hPa) and surface drag stress $\left(\mathrm{m}^{2} \mathrm{~s}^{-2}\right.$ ). Coloured areas: differences are statistically significant at $90 \%$

effect of blocking the advection of moisture, that would have otherwise been transported further east, therefore increasing cloudiness upstream of the Alps. Reduced drag over CWE is shown in Table 2 and Fig. 7, while increased moisture convergence over CWE and SEE in late spring and early summer is shown in Fig. $5 \mathrm{j}$. The anomaly of surface drag is much larger than its interannual standard deviation because it is closely related to the change of surface roughness. Moisture transport convergence shows much more variability, but it is highly statistically significant in May and June in CWE and SEE but is negligible in Ibe.

Though the main simulation that is analyzed in this study covers only $10 \mathrm{yr}$, our approach follows a practice that is common to other studies (Heck et al. 2001), where boundary conditions are provided by meteorological reanalysis and are identical for PNV and anthropic climate, so that the only source of differences between the 2 simulations is the land cover. This approach limits the effect of multidecadal variability. However, a similar simulation for the previous 10 yr (1982-1991) has been carried out, producing the same, actually larger, effect for cooling and increased cloudiness (Fig. 8). In this different period SLP increase is larger (both in size and extension) and the cloudiness changes consistently. Therefore, the analysis of 2 different decades produced very similar results, showing that our results are statistically robust and not substantially influenced by multidecadal variability.

Other simulations where carried out in order to further explore the effect of anthropic land use on cloudiness and on this high SLP feature, by replacing PNV with the present land-use over small fractions of the model domain. No effect, neither on SLP, nor on cloudiness, nor on temperature was obtained considering separate replacements over SEE, the Alps, northern Italy, and CWE. On the other hand, a significant effect was obtained when PNV was replaced in the Extended Central Western Europe region (ECWE) 
marked in Fig. 9, whose left panel shows the change in SLP and the right panel the change in cloudiness. This suggests that a small cooling signal, triggered by locally increased evapotranspiration over CWE, increases SLP over the Alps and cloudiness over CWE. When, in the ANTcli simulation, anthropic land use over the whole model domain increases evapotranspiration over much larger areas, cooling and the estab-

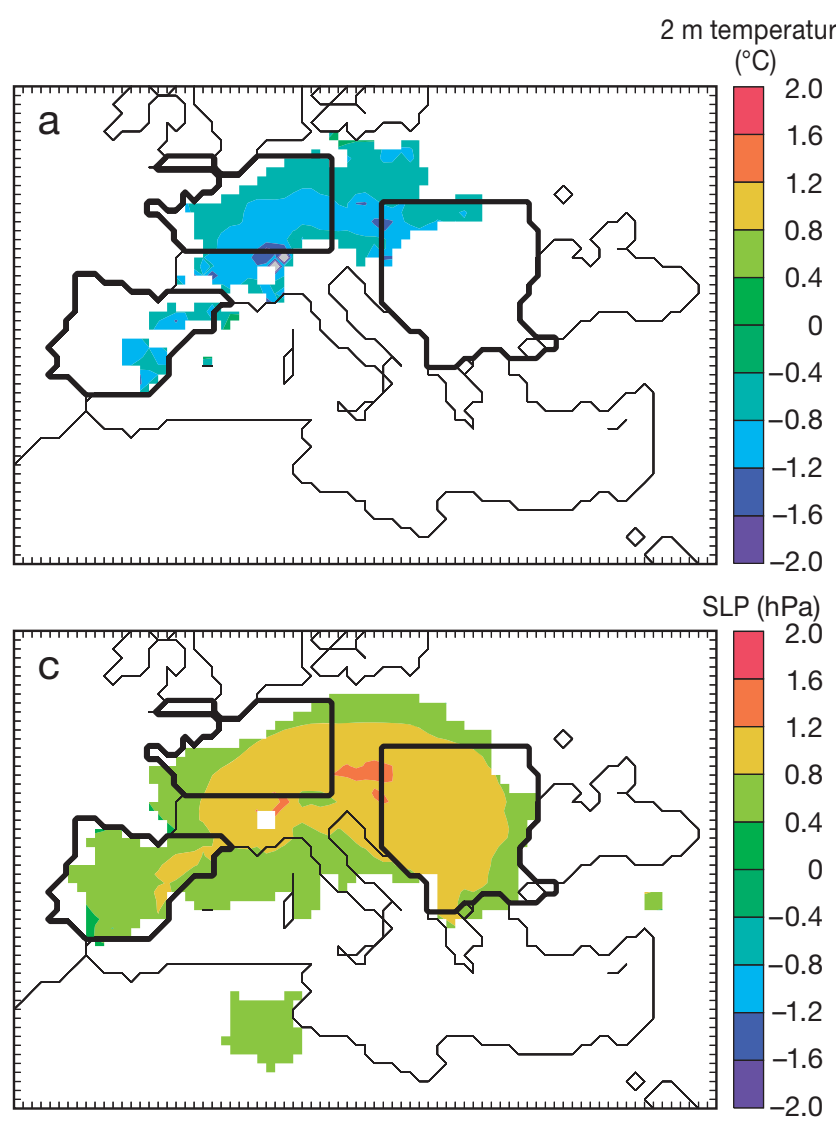

lishment of the high pressure are somehow nonlinearly enhanced, and have a much larger effect than when only BFR is involved. Repeating the BFR experiment, but assigning to the LCTs the stomata resistance of deciduous broadfleaf trees, cancels any effect on climate, showing that the main cause is the increased release of moisture, with the reduction of drag and albedo playing (if any) a minor role.

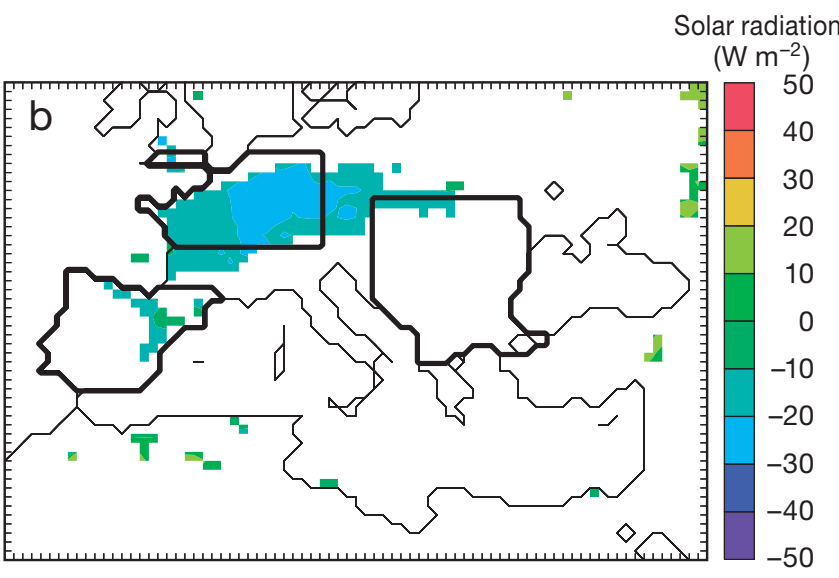

Fig. 8. Differences between ANTcli and PNVcli of (a) $2 \mathrm{~m}$ temperature, (b) incoming solar radiation and (c) sea level pressure, SLP. Coloured areas: differences are statistically significant at the $90 \%$ level

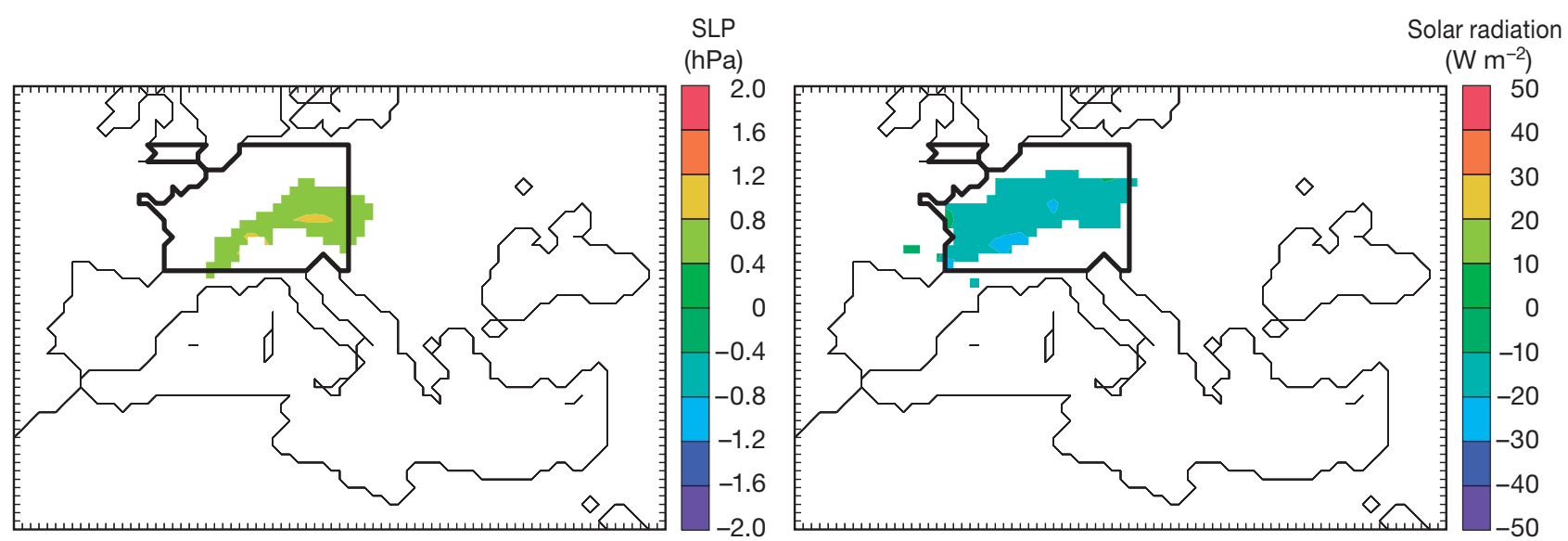

Fig. 9. Effect of anthropic land use over the Extended Central Western Europe region (inside thick black lines) on sea level pressure, SLP, (left) and incoming solar radiation (right) for Jun-Jul-Aug. Positive values denote areas where the anthropic climate has higher pressure and is cloudier. Colored areas: differences are statistically significant at the $90 \%$ level 
Other experiments were carried out (not shown) replacing the LCT over the whole RCM domain with a single type: either crop-farm, or deciduous broadleaf trees, or desert, or evergreen shrubs. These experiments consider the 3 yr period from 1993 to 1995. None of those is meant to be realistic and some of them imply large changes of temperature: dramatic warming in the case of desert, moderate cooling for deciduous broadleaf, dramatic cooling for crop-farm, and little net change for evergreen shrubs. In all these cases, a consistent change of SLP and cloudiness was observed, with large increase (decrease) cloudiness over central Europe being associated with SLP increase (decrease) and the pattern of SLP being associated with a reduction (increase) of surface temperature.

The use of a one-way nested model is obviously not capable of describing feedbacks of regional processes on global dynamical features. It is well known that atmosphere vegetation interaction at global scale can produce multiple equilibrium states of the atmosphere-vegetation system (Claussen 1998). Specifically for the Mediterranean region, temperature changes in this area have been shown travelling along the subtropical jetstream to the north Pacific and north America, propagating further across the north Atlantic towards northern Europe (Li 2006). It is possible that these temperature changes in the European and Mediterranean regions have global impacts and that they have effects in regions far from where they are generated. These large scale interactions affecting mid-latitude global dynamics, which are missing when an RCM is used, might change the effect that has been found for summer and produce significant effects in other seasons. Further, the importance of increased albedo due to increased reflectance of snow-covered areas that are not masked by forests (e.g. Bonan et al. 1995), is not evident in our study, presumably because the limited size of the area affected by this factor is not sufficient to overcome the noise due to the large climate variability of mid-latitudes in winter.

Note that the changes of partitioning between sensible and latent heat flux and indirect effects of soil moisture in our study are consistent with previous studies (e.g. Seneviratne et al. 2006, Zampieri et al. 2009). Though changes in the global carbon cycle are not considered in our results, other studies (e.g Bala et al. 2007) suggest that their role is secondary with respect to that of albedo and evapotranspiration that are investigated in this study.

Our results contrast with Heck et al. (2001), whose numerical simulations reveal that anthropic land use produces a drier and warmer spring, followed by a cooler and wetter summer. Differences are associated mainly with the large reduction of evapotranspiration over southern Europe, which is associated with anthro- pogenic land use in Heck et al. (2001); this reduction is smaller in our simulation. The lower evapotranspiration in Heck et al. (2001) simulations of the anthropic climate produces higher spring temperatures, which are partially reversed in summer when PNV has exhausted the soil moisture over large parts of southern Europe. This second opposite effect does not occur in our simulation. The average annual cycle of LAI (Fig. $5 g$ ) explains the differences between Heck et al. (2001)'s results and ours. The results of Heck et al. (2001) are strongly dependent on what happens over Iberia (where their analysis is focused) and the northeastern Mediterranean areas. Changes of LAI over Ibe have the same sign in both Heck et al. (2001) and our studies, but they are much smaller in ours. Consequently, the increase of evapostranspiration in our study does not trigger the dramatic decrease of soil moisture that causes the summer warming in Heck et al. (2001). On the other hand, our simulations show a large increase of LAI over the Balkan region, where high water availability ensures that soil moisture is not a limiting factor for evapotranspiration in spring and early summer and, consequently, anthropic cooling can continue for almost the whole growing season. Moreover, the increased cloudiness over CWE is not present in Heck et al. (2001) who comment only on a minor change over Spain. This disagreement shows that results clearly depend on the adopted model, and that differences in PNV - in the representation that the model adopts for the properties of vegetation, and in the description of hydrology and soil water balance - are very important.

Finally, since the adopted representation of LCTs in this version of the RegCM model grid could overestimate the influence of anthropic LCTs on the parameters describing the land surface (see description of the model in Section 2), our study might overestimate the associated cooling effect. Further, the cool bias in the present climate simulation over western Europe might be partially due to an exaggerated extension of the area attributed to crops and farms. Both the accuracy of VERDE and of RegCM in reproducing PNV and climate, respectively, are a source of uncertainty in this study. VERDE has been shown to be reasonably accurate by Zampieri \& Lionello (2010). To show that the bias of the present climate computation by RegCM does not affect the PNV feedback, we computed the climate (denoted a CRUcli) associated to the PNV distribution computed by VERDE on the CRU climatology shown in Fig. 1c, and were able to assess separately the influence of RegCM bias as a possible source of error in the coupled system. Fig. 10 shows the summer temperature difference between the CRUcli and PNVcli. Temperatures of the 2 simulations differ significantly in a zonal band that extends eastward from the 


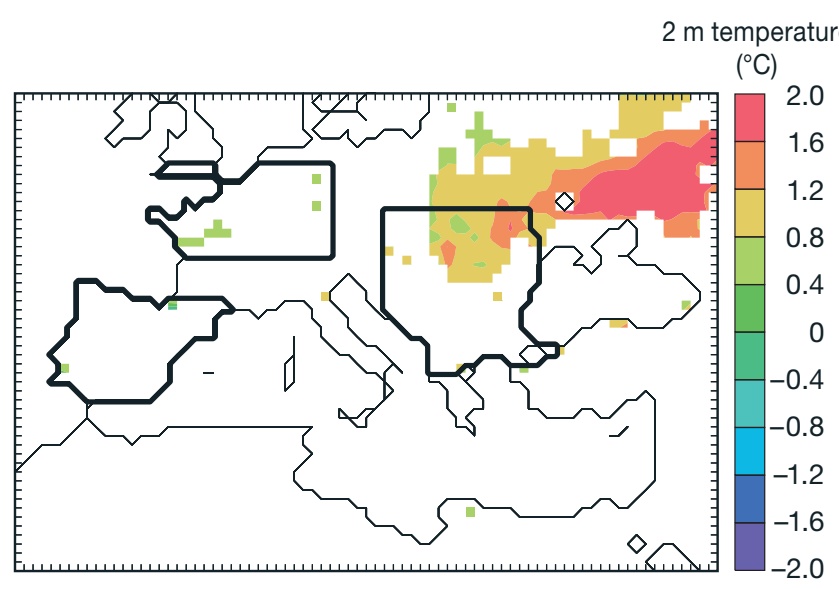

Fig. 10. Differences between CRUcli and PNVcli of $2 \mathrm{~m}$ temperature $\left({ }^{\circ} \mathrm{C}\right), 1992-2001$

north eastern part of the Balkans region. In this area CRUcli is characterized by a hotter climate mainly because the overestimation of precipitation by RegCM determines the presence of forest instead of grass and semi-desert. Therefore, the RegCM bias may eventually affect our results only for a small part of the Balkans region and in an area further east of the Balkans, which is not discussed in the paper. Most importantly, there is no difference in cloudiness between CRUcli and PNVcli, showing that the activation of the process involving the cloud feedback, which is the most interesting outcome of this study, is not affected by the RegCM bias.

\section{CONCLUSIONS}

Anthropic land use changes have an important effect at a regional scale in summer. Crops and farming have most likely cooled European summer surface temperatures over SEE through the direct effect of increased evapotranspiration, and over CWE through increased cloudiness. This suggests that restoring natural vegetation would not be an effective way of mitigating climate change for summer temperature at a regional scale. Moreover, it might be speculated that this cooling effect of anthropic land use has masked the anthropogenic warming signal in some European areas. However, since the percentage of land used for crops and farming has remained nearly constant in Europe during the 20th century (Ramankutty et al. 2002), it is likely that a masking effect on the anthropic warming signal is negligible. Results of single model simulations, however, should always be considered with caution, and are dependent on the vegetation and hydrology parameterizations, as they influence the soil moisture and the evapotraspiration amounts.
The effect of evapotranspiration (associated with reduced stomatal resistance and increased LAI) is the most important factor. Crops and farms significantly increase summer albedo, but the resulting effect is smaller in comparison to that of evapotranspiration, so that surface temperature is not appreciably affected. There is also a statistically significant reduction of surface drag, but no evidence of a robust associated change of surface circulation, except for a local (albeit not statistically significant) effect on precipitation in coastal areas.

The increased cloudiness is a key factor for the summer cooling over CWE, which can be due either to an increase in cloud production due to a reduced lifting condensation level, or to a dynamical feedback involving the establishment of a thermal high pressure over central Europe, and the blocking of eastward moisture transport.

This study confirms previous results showing that land use can have an important effect on European climate, even when only regional effects are considered, and that this is in some ways similar to the effect in other areas (e.g. California, Kueppers et al. 2007). The induced signal is comparable, though clearly smaller than the size of the signal generally attributed to the future increases in green house gases, and it is larger than the warming observed during the 20th century.

For actual management of the territory, natural vegetation should not only be considered as a tool only for climate change mitigation. Recreational and environmental issues should also be considered, including the proper functioning of ecosystem and preservation of biodiversity. Moreover, there might be practical benefits for ecosystems adapted to the shade of trees with respect to being exposed to solar radiation in absence of canopy cover, which should be accounted for while analyzing the effect of vegetation on the environment.

Our results are certainly open to future revision, because of several factors: the interactions of vegetation with climate are not fully resolved and the uncertainty associated with the involved processes is not sufficiently quantified; the model framework adopted in these regional simulations is oversimplified; a full coupling between vegetation and climate, including the description of the transition leading to a new equilibrium, is needed. However, in spite of these limitations, our method is robust, and our results show that, in general, anthropic land use has had an impact on climate conditions, and has likely reduced summer temperatures over central Europe.

Acknowledgements. M. Zampieri was partially supported by the CLIMESCO FISR-MIUR project. 


\section{LITERATURE CITED}

Bala G, Caldeira K, Wickett M, Phillips TJ, Lobell DB, Delire C, Mirin A (2007) Combined climate and carbon-cycle effects of large-scale deforestation. Proc Natl Acad Sci USA 104:6550-6555

Betts RA (2000) Offset of the potential carbon sink from boreal forestation by decreases in surface albedo. Nature 408: 187-200

Betts RA, Falloon PD, Goldewijk KK, Ramankutty N (2007) Biogeophysical effects of land use on climate: model simulations of radiative forcing and large-scale temperature change. Agric For Meteorol 142:216-233

Bonan GB (1997) Effects of land use on the climate of the United States. Clim Change 37:449-486

Bonan GB (2008) Forests and climate change: forcings, feedbacks, and the climate benefits of forests. Science 320: 1444-1449

Bonan GB, Chapin FS III, Thompson SL (1995) Boreal forest and tundra ecosystems as components of the climate system. Clim Change 29:145-167

Charney JG, Quirk WJ, Chow SH, Kornfield J (1977) A comparative study of the effects of albedo change on drought in semi-arid regions. J Atmos Sci 34:1366-1385

Christensen JH, Hewitson B, Busuioc A, Chen A and others (2007) Regional Climate Projections. In: Solomon S, Qin D, Manning $\mathrm{M}$, Chen $\mathrm{Z}$ and others (eds) Climate Change 2007: The physical science basis. Contribution of Working Group I to the Fourth Assessment Report of the Intergovernmental Panel on Climate Change. Cambridge University Press, Cambridge, p 847-940

Claussen M (1998) On multiple solutions of the atmospherevegetation system in present-day climate. Global Biogeochem Cycles 4:549-559

Cohen J (1960) A coefficient of agreement for nominal scales. Educ Psychol Meas 20(1):37-46

> Deque M, Jones RG, Wild M, Giorgi F and others (2005) Global high resolution vs. regional climate model climate change scenarios over Europe: quantifying confidence level from PRUDENCE results. Clim Dyn 25:653-670

Dickinson RE, Henderson-Sellers A, Kennedy PJ (1993) Biosphere-atmosphere transfer scheme (BATS) version 1 as coupled to the NCAR Community Climate Model. NCAR Technical Note NCAR/TN-387+STR

Eidenshink JC, Faundeen JL (1994) The 1 km AVHRR global land data set: first stages in implementation. Int J Remote Sens 15:3443-3462

- Feddema JJ, Oleson KW, Bonan GB, Mearns LO, Buja LE, Meehl GA, Washington WM (2005) The importance of land-cover change in simulating future climates. Sci 310: $1674-1678$

Foley JA, Levis S, Prentice IC, Pollard D, Thompson SL (1998) Coupling dynamic models of climate and vegetation. Glob Change Biol 4:561-579

Gibbard S, Caldeira K, Bala G, Phillips TJ, Wickett M (2005) Climate effects of global land cover change. Geophys Res Lett 32:L23705. doi:10.1029/2005GL024550

Giorgi F, Marinucci MR, Bates GT (1993a) Development of a second generation regional climate model (REGCM2). I. Boundary layer and radiative transfer processes. Mon Weather Rev 121:2794-2813

Giorgi F, Marinucci MR, Bates GT, DeCanio G (1993b) Development of a second generation regional climate model (REGCM2). II. Convective processes and assimilation of lateral boundary conditions. Mon Weather Rev 121: $2814-2832$
Govindasamy P, Duffy B, Caldeira K (2001) Land use changes and northern hemisphere cooling. Geophys Res Lett 28: 291-294

> Heck P, Lüthi D, Wernli H, Schär C (2001) Climate impacts of European scale anthropogenic vegetation changes. A sensitivity study using a regional climate model. J Geophys Res 106:7817-7835

- Henderson-Sellers A, McGuffie K, Gross G (1995) Sensitivity of global climate model simulations to increased stomatal resistance and CO2 increases. J Clim 8:1738-1756

- Kalnay E, Cai M (2003) Impact of urbanization and land use on climate change. Nat 423:528-531

> Kueppers LM, Snyder MA, Sloan LC (2007) Irrigation cooling effect: regional climate forcing by land-use change. Geophys Res Lett 34:L03703. doi:10.1029/2006GL028679

Li ZX (2006) Atmospheric GCM response to an idealized anomaly of the Mediterranean sea surface temperature. Clim Dyn 27:543-552

New MG, Hulme M, Jones PD (2000) Representing twentieth century space time climate fields. II. Development of a 1901-1996 mean monthly terrestrial climatology. J Clim 13:2217-2238

> Pal JS, Small EE, Eltahir EAB (2000) Simulation of regional scale water and energy budgets: representation of subgrid cloud and precipitation processes within RegCM. J Geophys Res 105:29579-29594

> Pinto E, Shin Y, Cowling SA, Jones CD (2009) Past, present and future vegetation-cloud feedbacks in the Amazon Basin. Clim Dyn 32:741-751

> Pitman AJ, Narisma GT, Pielke RA, Holbrook NY (2004) Impact of land cover change on the climate of southwest Western Australia. J Geophys Res 109:D18109. doi:10. 1029/2003JD004347

Ramankutty N, Foley JA (1999) Estimating historical changes in global land cover: croplands from 1700 to 1922. Global Biogeochem Cycles 13:997-1027

Ramankutty N, Foley JA, Olejniczak NJ (2002) People on the land: changes in global population and croplands during the 20th century. Ambio 31:251-257

Sellers PJ (1992) Biophysical models of land surface processes. In: Trenberth KE (ed) Climate system modeling. Cambridge University Press, Cambridge, p 451- 490

Sellers PJ, Dickinson RE, Randall DA, Betts AK and others (1997) Modeling the exchanges of energy, water, and carbon between continents and the atmosphere. Sci 275:502-509

- Seneviratne SI, Lüthi D, Litschi M, Schär C (2006) Landatmosphere coupling and climate change in Europe. Nature 443:205-209

Simmons AJ, Gibson JK (2000) The ERA-40 Project Plan, ERA-40 Project Report Series n.1. ECMWF, Reading

Sitch S, Brovkin V, von Bloh W (2005) Impacts of future land cover changes on atmospheric $\mathrm{CO}_{2}$ and climate. Global Biogeochem Cycles 19:GB2013

Willis KJ (1994) The vegetational history of the Balkans. Quat Sci Rev 13:769-788

Yang ZL, Dickinson RE (1996) Description of the biosphereatmosphere transfer scheme (BATS) for the Soil Moisture Workshop and evaluation of its performance. Global Planet Change 13:117-134

Zampieri M, Lionello P (2010) Simple statistical approach for computing land cover types and potential natural vegetation. Clim Res 41:205-220

Zampieri M, D'Andrea F, Vautard R, Ciais P, de NobletDucoudré N, Yiou P (2009) Hot European summers and the role of soil moisture in the propagation of Mediterranean drought. J Clim 22:4747-4758 